\title{
Serial circulating omega 3 polyunsaturated fatty acids and healthy ageing among older adults in the Cardiovascular Health Study: prospective cohort study
}

In this article (BMJ 2018;363:k4067, doi:10.1136/bmj.k4067), figures 1 and 2 were mistakenly put in the wrong order: figure 1 should have been figure 2 , and figure 2 should have been figure 1 . The figure captions remain correct and stay the same. As a result, the wrong image for figure 2 was inserted in the 20
October 2018 print issue; the following URL links to the correct image: https://www.bmj.com/content/bmj/363/bmj.k4067/F2. large.jpg that should have been in its place.

This figure order has since been corrected in the online version and the online PDF. 